\title{
$\checkmark$ Research Square \\ Genetic diversity of fragmented natural populations of Pyrenacantha volubilis Wight. in India
}

\section{Arjun Ramachandran ( $\nabla$ arjuram123@gmail.com )}

Forest College and Research Institute - Hyderabad @ Mulugu https://orcid.org/0000-0002-7840-8458

\section{A. V. Santhoshkumar}

Kerala Agricultural University

\section{Deepu Mathew}

Kerala Agricultural University

\section{Manju Elizabeth}

Kerala Agricultural University

Jiji Joseph

Kerala Agricultural University

\section{Ramesh Vasudeva}

University of Agricultural Sciences Dharwad

\section{Research Article}

Keywords: Camptothecin, ISSR, UPGMA, NJ tree, Hierarchical clustering, Jaccard's similarity coefficient

Posted Date: September 8th, 2021

DOI: https://doi.org/10.21203/rs.3.rs-833939/v1

License: (c) (i) This work is licensed under a Creative Commons Attribution 4.0 International License.

Read Full License 
Arjun Ramachandran ${ }^{1,2,3 *}$, A. V. Santhoshkumar ${ }^{2}$, Deepu Mathew ${ }^{2}$, Manju Elizabeth ${ }^{2}$, Jiji Joseph $^{2}$, Vasudeva Ramesh $^{3}$

https://orcid.org/0000-0002-7840-8458; https://orcid.org/0000-0003-4253-8581; https://orcid.org/0000-00022941-1060; https://orcid.org/0000-0003-2731-3501; https://orcid.org/0000-0002-0153-2477; https://orcid.org/0000-0001-8922-805X

${ }^{1}$ Forest College and Research Institute - Mulugu, Hyderabad, Telangana, India.

${ }^{2}$ Kerala Agricultural University, Kerala, India.

${ }^{3}$ University of Agricultural Sciences - Dharwad, Karnataka, India.

*arjuram123@gmail.com

\section{Abstract}

Pyrenacantha volubilis Wight. is a dioecious liana occurring in small, clustered populations. The species had no documented use until the recent past, when it was identified to be a source of a highly traded anti-cancer drug camptothecin. In the present study, we examine the genetic diversity of 12 fragmented natural populations of $P$. volubilis using morphological and molecular traits. Twelve polymorphic Inter Simple Sequence Repeat (ISSR) primers and 29 agromorphological traits were used to discriminate the populations using UPGMA and NJ tree algorithms respectively. The ISSR amplicon profile had 133 distinct bands. The maximum number of amplicons were produced by UBC 844 (20 bands) and the average polymorphism was 80.07 per cent. The dendrograms obtained based on molecular and agro-morphological data are in close congruence. The Thiruvananthapuram population stood apart in both the analyses as a discrete outgroup: perhaps a consequence of local adaptation. Substantial genetic diversity exists among populations. This could be tapped in domestication, which is the only way forward for the long-term survival of this species. We also report for the first time a standardized method for extraction of genomic DNA from the leaves of $P$. volubilis.

Keywords: Camptothecin, ISSR, UPGMA, NJ tree, Hierarchical clustering, Jaccard's similarity coefficient

\section{Declarations}

Funding acknowledgements: The first author received the INSPIRE Junior Research Fellowship (IF180651) from Department of Science and Technology, Government of India and research contingency grant from Kerala Agricultural University, Kerala, India. 
Ethics approval: Not applicable

Consent to participate: Not applicable

Consent for publication: Not applicable

Availability of data and material: Not applicable

Code availability: Not applicable

Authors' contributions: Not applicable

\section{Introduction}

Pyrenacantha volubilis Wight. (Icacinaceae) is a newly identified source of camptothecin (CPT), a highly valued anti-cancer molecule (Ramesha et al. 2013). P. volubilis is a highly branched and twining dioecious liana, which occurs in small, clustered populations across Sri Lanka, Indo-China, Hainan and India. In India, it has been reported from the peninsular states of Maharashtra, Karnataka, Kerala, Tamil Nadu and Andhra Pradesh (Pullaiah and Chennaiah 1997; Kumar et al. 2001; Sasidharan and Renu 2013). Due to the absence of any documented local knowledge on its use, it has been a 'blind spot' to most botanists and natural history experts (Wandersee and Schussler 1999; Ramachandran and Vasudeva 2020). Many of the distribution reports are historical and recent surveys have concluded that the species has been extirpated from most part of its historical distribution. The present distribution of the species in India is only from a few patches in Tamil Nadu and Kerala states of India (Ramachandran 2017). Despite its rarity, disjunct distribution, presence of several threats as well as commercial potential, the IUCN has not evaluated the species for its conservation status (Shaanker et al. 2008; Ved et al. 2016). Domestication of this plant has only been initiated since the past few years (Ramachandran and Vasudeva 2020). Only limited literature is available on the utilitarian value of P. volubilis (Ramachandran 2020; Ramachandran et al. 2021).

The knowledge on this species is plagued with several lacunae, the most prominent being the Wallacean and Prestonian shortfalls (Lomolino 2004; Cardoso et al. 2011). We assume that the $P$. volubilis populations are native to peninsular India. Historical records by Fischer (1917), Pate (1917) and Fischer (1921) report the presence of $P$. volubilis in Nellore district, the then Presidency of Madras and Annamalai hills of Coimbatore district. Lack of 
knowledge (Ramachandran and Vasudeva 2020) are indicative that $P$. volubilis might not have been introduced for any particular use during the past.

The present study was conducted with the objective of dissecting the genetic diversity in the fragmented natural populations of $P$. volubilis. Amplicon profiles using ISSR primers and data on agro-morphological traits were employed for the purpose. This paper standardizes for the first time, the DNA extraction protocol from $P$. volubilis.

\section{Materials and methods}

\subsection{Plant material and the study area}

The leaf samples for the experiment on molecular genetic diversity of $P$. volubilis were collected through extensive field visits throughout the distribution range of the species, in Tamil Nadu and Kerala states of India (Figure 1, Table 1). Bulked leaf samples from the 12 natural populations, viz. Thiruvananthapuram, Vallathirakkottai, Sendirakillai, Otteri, Karukkai, Pondi, Puthupattu, Mangalam, Kizhoor, Villiampakkam, Pazhaiyasivaram and Walajabad, were collected in such a manner that the sample represented individuals from different parts of each population. Due to the unique growth habit of the plant, individual plant identity could not be maintained in the collections. The laboratory work and analysis of molecular genetic diversity was conducted at the College of Forestry - Vellanikkara, Kerala Agricultural University, Thrissur, Kerala, India from September 2019 to May 2020. The data agro-morphological data was acquired from the gene bank for the species established at College of Forestry-Sirsi, University of Agricultural Sciences-Dharwad, Karnataka, India.

\subsection{Data on agro-morphological traits}

Data on 29 independent agro-morphological traits of the 12 natural populations of $P$. volubilis were used for this study (Supplementary material: S1). The data included morphological (fruit, seed, leaf), seedling growth and camptothecin yield traits. Qualitative traits were converted to a nominal scale. These traits were the shape, texture, margin of leaf and the type of leaf tip. The quantitative traits included the length, width and weight of fruits and seeds, pulp weight, leaf length: leaf width, leaf area, petiole length, petiole diameter at leaf base, diameter of fruit-bearing stem segment, number of frutescence per random $50 \mathrm{~cm}$ of fruit bearing stem segments, number of fruits per infructescence, ground diameter, shoot length, internodal length, number of leaves, number of branches and air-dry weights of root, stem, leaf of two-year old seedlings, and camptothecin content of root, stem and whole seeds. The morphological and seedling growth data were averaged for a minimum of five plants 
from each population. The camptothecin (yield) traits were taken as an average of three fruiting individuals from each population.

\subsection{Extraction of genomic DNA and thermal amplification}

DNA extraction was done by modifying the CTAB protocol by Rogers and Benedich (1994). Phenol: Chloroform: Isoamyl alcohol (25:24:1) treatment was done as per Vandrey and Stutz (1973) to reduce protein contamination. The quality of DNA thus obtained was checked by electrophoresing (horizontal electrophoresis unit - BioRad, USA) in $0.8 \%$ agarose gel (in $1 \times$ TBE buffer), stained with ethidium bromide. The purity and quantity of the DNA were estimated using a Nano Drop Spectrophotometer (Jenway - Genova Nano).

Sixteen ISSR primers reported to produce consistent, discernible and reproducible bands in Nothapodytes nimmoniana, another camptothecin producing plant from the region belonging to family Icacinaceae (Kareem et al. 2011) were attempted (Table 2). The reaction mixture consisted of template DNA ( $\left.2 \mu \mathrm{L}-100 \mathrm{ng} \mu \mathrm{L}^{-1}\right)$, Emerald Amp GT PCR (Takara) master mix (5 $\mu \mathrm{L})$, ISSR (Sigma-Aldrich) primer (1.5 $\mu \mathrm{L}-5 \mu \mathrm{M})$ and nuclease-free water $(1.5 \mu \mathrm{L})$. Once all the other PCR conditions were standardized, the annealing temperature was refined by running gradient PCR from $38^{\circ} \mathrm{C}$ to $58^{\circ} \mathrm{C}$. The PCR conditions were programmed and saved in the thermal cycler (Eppendorf AG22331).

Thermal cycling programme had a hotstart at $94^{\circ} \mathrm{C}$ for 4 minutes, followed by 35 cycles each comprising denaturation at $94^{\circ} \mathrm{C}$ for $45 \mathrm{~s}$, annealing at the primer specific temperature for 1 minute and primer extension at $72^{\circ} \mathrm{C}$ for for 2 minutes. This was followed by the final extension at $72^{\circ} \mathrm{C}$ for $8 \mathrm{~min}$ and the samples were maintained at $4{ }^{\circ} \mathrm{C}$. The PCR products have been electrophoresed in $1.6 \%$ agarose gel along with ProxiO $100 \mathrm{bp}$ DNA Ladder Plus (SRL) gel profiles were documented.

\subsection{Hierarchical cluster analysis}

The twelve natural populations were grouped into classes by taking amplification profiles of the 12 ISSR primers (4 out of the 16 ISSR primers did not amplify) as surrogates for the genotype. The presence-absence of an amplicon at a locus was represented using the 1-0 format. The cluster dendrograms were created using Unweighted Pair Group Method with Arithmetic mean (UPGMA) of NTSYSpc v.-2.02i (Rohlf, 1993). The similarity was computed using the Jaccard's similarity coefficient (J) algorithm of the SimQual programme.

The dendrogram thus obtained was compared with the data on independent agro-morphological traits of the populations. This was used as a surrogate of the phenotype for hierarchical cluster analysis. For the analysis, the 
qualitative and quantitative data were transformed into 0-1 range. The single linkage, Euclidean distance model of Neighbour Joining (NJ) tree algorithm in Minitab v. 17.0 software was used to explain the phenotypic variation in agro-morphological characteristics. The phenotypic data were used for the purpose of comparison.

\section{Results and discussion}

\subsection{Standardization of DNA extraction protocol}

Due to better storability (up to 2.5 months under refrigerated conditions) and reduced presence of polyphenols, mature leaves were preferred over young and tender leaves for the genomic DNA extraction from P. volubilis. The use of phenol: chloroform: isoamyl alcohol (25:24:1) mixture was effective in minimizing protein contamination in the DNA as was observed by Vandrey and Stutz (1973) in Euglena gracilis. The DNA extracted from all the populations was free from RNA and protein contamination, having $\mathrm{OD}_{260 / 280}$ values of 1.8-2.0. The

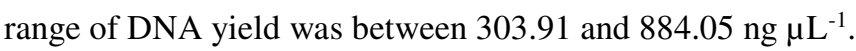

\subsection{Primer screening}

Of the 16 ISSR primers attempted (Table 2), 12 primers have generated polymorphic and reproducible bands. Primers UBC 822, UBC 857, UBC 873 and UBC 895 have not yielded any band across varying annealing temperatures (Table 2). Molecular genetic diversity assessment was therefore done with 12 ISSR primers viz. UBC 827, UBC 834, UBC 844, UBC 845, UBC 854, UBC 866, UBC 874, UBC 876, UBC 881, UBC 887, UBC 902 and UBC 906. Kareem et al. (2011) employed the same 16 ISSR primers to unravel the genetic diversity in Nothapodytes nimmoniana, and was able to get amplification using all the primers. On the other hand, out of the 16 ISSR primers used to understand the molecular level genetic diversity of Juniperus phoenicea, only three amplified to produce scorable bands (Meloni et al. 2006).

\subsection{ISSR primer analysis of $P$. volubilis}

The 12 ISSR primers have yielded three to twenty bands (Table 3) and a total of 133 distinct bands were retrieved from the amplicon profile (Figure 2). The maximum number of amplicons were produced by UBC 844 (20 bands) and the lowest by UBC 881 (three bands). The remaining primers generated 7 (UBC 876), 9 (UBC 834, UBC 906), 10 (UBC 874, UBC 887, UBC 902), 11 (UBC 866), 12 (UBC 827), 14 (UBC 854) and 18 (UBC 845) bands each. The number of polymorphic bands varied from three bands for primers UBC 876 and UBC 881 to 19 bands for primer UBC 844. The minimum percentage polymorphism was for UBC 876 (42.86 \%) followed by UBC 834 (44.44\%). All bands were polymorphic for three primers viz. UBC 866, UBC 881 and UBC 887, 
which had 100 per cent polymorphism. This includes primer UBC 881, which produced the lowest number of bands (three). The primer that generated the maximum number (20) of bands, i.e. UBC 844, had 19 polymorphic bands, resulting in 95 per cent polymorphism. The average polymorphism was 80.07 per cent.

Based on the banding pattern, among the 12 primers used in the experiment 10 were markers for 10 out of the 12 populations of $P$. volubilis (Table 4). Polymorphic primers UBC 876 and UBC 902 were not helpful in discriminating $P$. volubilis populations. The ten markers, which produced unique bands can help to identify all the populations studied, except for populations Pondi and Mangalam. Primer UBC 827 was the most helpful in discriminating $P$. volubilis populations because its amplicon profile provides unique bands for Vallathirakkottai and Thiruvananthapuram and an absence of a single specific band each for Pazhaiyasivaram and Kizhoor populations. Thus, this single marker helps in discerning four (one-third) of the twelve populations of $P$. volubilis considered for this study. Similarly, the only Kerala population of $P$. volubilis sampled for this experiment i.e., Thiruvananthapuram can be differentiated easily based on the amplification profile of primer UBC 881 . Although this primer produced only three bands, one out of these is unique to the Thiruvananthapuram population.

In a study on the genetic diversity of Nothapodytes nimmoniana, 73.7 per cent polymorphism (76 out of 103 distinct bands) was observed using the same 16 primers (Table 3) as used in the present study (Kareem et al. 2011). Genetic diversity of 12 Ethiopian populations of the dioecious tree Hagenia abyssinica was assessed using eight ISSR primers. Jaccard's similarity coefficient ranged between 0.53 and 0.66 , and 81 per cent of the 104 scorable bands were polymorphic (Feyissa et al. 2007). Similar to these studies, the present study on P. volubilis reports a high level of percentage polymorphism, which is an indication of high genetic diversity among the 12 populations considered in the study.

Mediterranean populations of Juniperus phoenicea were subjected to genetic diversity assessment using 16 ISSR primers. Out of these, only three amplified and produced reproducible, polymorphic bands with 45 per cent polymorphism (Meloni et al. 2006). When compared with mapping information of the populations, the results of that study revealed that gene flow was curtailed by geographic isolation. Nine populations of the endangered plant Emmenopterys henryi endemic to China were subjected to ISSR marker analysis by Li and Jin (2007). The low level of genetic diversity among the populations was identified using the information on the percentage polymorphic loci (22.56 per cent). The poor genetic diversity has been attributed to specific evolutionary processes and anthropogenic drivers like landscape fragmentation and the resultant isolation of populations. Taking hints from such studies, the conservation implication of the results on P. volubilis is quite alarming. 
Although not characterized by low genetic diversity as yet, the large-scale fragmentation (Ramachandran and Vasudeva 2020) of the landscape where P. volubilis grows naturally could eventually lead to an irreversible pauperization of genetic diversity of this potential cash crop.

\subsection{Cluster analysis based on molecular data and agro-morphological traits}

The genetic relationship between the various populations has been investigated using the ISSR amplicon profile. The $P$. volubilis populations were classified into seven distinct classes based on the amplicon profiles (Figure 3). The per cent similarities ranged from 68 to 80 . A cut off value based on similarity coefficients was not assigned as the 12 primers were able to amplify only an infinitesimally small portion of the possibly complex genome of $P$. volubilis. As the genomic representation is too little, a cut off value could bias the results. The only population from Kerala i.e., Thiruvananthapuram formed an outgroup showing the highest dissimilarity (32 per cent) with the $P$. volubilis populations from Tamil Nadu. The clusters followed a North-South gradient.

Based on agro-morphological traits, the 12 populations were clearly discriminated into eight major clusters (Figure 4). The single $P$. volubilis population from Kerala (Thiruvananthapuram) clustered as an outgroup of the 11 populations from Tamil Nadu state.

The dendrograms obtained based on molecular and agro-morphological data are in close congruence. The results are also in line with the clinal variations reported for fruit, seed, leaf, seedling and yield traits of $P$. volubilis (Ramachandran and Vasudeva 2020) across latitudinal gradients and geographical proximity of seed sources. The Thiruvananthapuram population stood apart in both the analyses as a discrete outgroup. There is a possibility that the Tamil Nadu populations could have developed a separate spectrum of adaptive traits for the drier and warmer Tamil Nadu agro-ecological conditions compared to the more humid conditions of Kerala. The resultant divergence in the gene pools could have been developed due to several years of competition, natural selection and survival of the fittest. Local adaptation could be the causal agent for the out-grouping of Thiruvananthapuram population (Kawecki and Ebert 2004). Such variations have been observed in Populus tremula (Ingvarsson and Bernhardsson 2020), Arabidopsis lyrata (Hamala and Savolainen 2019), Holcus lanatus (Macel et al. 2007) and Lotus corniculatus (Macel et al. 2007).

The anthropogenic fragmentation of landscapes where $P$. volubilis grows, over the very recent geological past could have played some role in controlling gene flow over short distances. This could explain the diversity among the Tamil Nadu populations of $P$. volubilis. The subtle gradations in climatic, edaphic and biotic variables contribute to such variations both at the genotypic as well as phenotypic level (Savolainen et al. 2007). In the 
present study, the clustering of the Tamil Nadu populations of $P$. volubilis based on both molecular data (surrogate for genotype) and agro-morphological data (surrogate of phenotype) is on similar lines. The Kanchipuram cluster (Walajabad, Pazhaiyasivaram, Villiampakkam populations), the Pondicherry cluster (Pondi, Puthupattu populations), Cuddallore-Chettinad cluster (Otteri, Karukkai, Sendirakillai populations) and the southern Tamil Nadu-Tiruchirappalli cluster (Vallathirakkottai) were clearly identifiable. However, populations from Mangalam and Kizhoor clustered as exceptions. Adaptative radiation of populations to environmental gradient as observed in clines has been elaborated in the seminal paper by Barton (1999). Evidences of the same are available from common garden studies in annual 'teosintes', a wild relative of Zea mays (Fustier et al. 2019). Collignon et al. (2002) and Kremer et al. (2002) attribute the lion-share of variation in adaptive traits to selection in recent times through comparison of molecular and quantitative trait data.

In conclusion, genetic diversity assessment of $P$. volubilis points to high genetic diversity, the full potential of which must be tapped for domestication. In the near future, the effects of landscape fragmentation and other anthropogenic deterrents to gene flow are likely to show an impact on the genetic architecture of populations. This could engender the natural populations of $P$. volubilis through reduced reproductive fitness or adaptive traits resulting from the breeding of closely related individuals. Reduction in genetic diversity is likely to be lethal to populations of a dioecious plants such as $P$. volubilis in which cross-pollination is the only option. Variations in environmental variables, geographical isolation and human-induced factors could be the major determinants for the genetic divergence.

\section{References}

Barton NH (1999) Clines in polygenic traits. Genet Res 74(3):223-236. DOI: 10.1017/S001667239900422X

Cardoso P, Erwin TL, Borges PA, New TR (2011) The seven impediments in invertebrate conservation and how to overcome them. Biol Conserv 144(11):2647-2655. DOI: 10.1016/j.biocon.2011.07.024

Collignon AM, Sype HVD, Favre JM (2002) Geographical variation in random amplified polymorphic DNA and quantitative traits in Norway spruce. Can J For Res 32(2):266-282. https://doi.org/10.1139/x01-198

Feyissa T, Nybom H, Bartish IV, Welander M (2007) Analysis of genetic diversity in the endangered tropical tree species Hagenia abyssinica using ISSR markers. Genet Resour Crop Evol 54(5):947-958. DOI: $10.1007 / \mathrm{s} 10722-006-9155-8$ 
Fischer CEC (1917) Flora of Nellore. Report submitted to the Presidency of Madras. Available from: https://www.google.co.in/urlshodhganga.inflibnet.ac.in

Fischer CEC (1921) A survey of the flora of the Anamalai hills in the Coimbatore district Madras Presidency: Records of the Botanical Survey of India, Madras Presidency

Fustier MA, Martínez-Ainsworth NE, Aguirre-Liguori JA, Venon A, Corti H et al (2019) Common gardens in teosintes reveal the establishment of a syndrome of adaptation to altitude. PLoS Genet 15(12):1008512. https://doi.org/10.1371/journal.pgen.1008512

Hämälä T, Savolainen O (2019) Genomic Patterns of Local Adaptation under Gene Flow in Arabidopsis lyrata. Mol Biol Evol 36(11):2557-2571. https://doi.org/10.1093/molbev/msz149

Ingvarsson PK, Bernhardsson C (2020) Genome-wide signatures of environmental adaptation in European aspen (Populus tremula) under current and future climate conditions. Evol Appl 13(1):132-142. DOI: $10.1111 /$ eva.12792

Kareem VKA, Rajasekharan PE, Mini S, Kumar TV (2011) Genetic diversity and structure of threatened anticancerous plant Nothapodytes nimmoniana as revealed by ISSR analysis. Plant Gen Resour 9(4):506-514. doi: $10.1017 / \mathrm{S} 1479262111000803$

Kawecki TJ, Ebert D (2004) Conceptual issues in local adaptation. Ecol Lett 7(12):1225-1241. doi: $10.1111 / j .1461-0248.2004 .00684 . x$

Kremer A, Kleinschmit J, Cottrell J, Cundall EP, Deans JD et al (2002) Is there a correlation between chloroplastic and nuclear divergence, or what are the roles of history and selection on genetic diversity in European oaks? For Ecol Manag 156(1-3):75-87. https://doi.org/10.1016/S0378-1127(01)00635-1

Kumar ESS, Yeragi SS, Babu KN, Khan AES (2001) Pyrenacantha volubilis Hook. (Icacinaceae) - A new record for Kerala state. J Econ Taxon Bot 25(3):729-731.

Li JM, Jin ZX (2007) Genetic structure of endangered Emmenopterys henryi Oliv. based on ISSR polymorphism and implications for its conservation. Genetica 133(3):227-234. DOI: 10.1007/s10709-007-9204-z

Lomolino MV (2004) Conservation biogeography. In: Lomolino MV, Heaney LR (eds) Frontiers of Biogeography: new directions in the geography of nature, Sinauer Associates, Sunderland, Massachusetts, pp 293-296 
Macel M, Lawson CS, Mortimer SR, Šmilauerova M, Bischoff A et al (2007) Climate vs. soil factors in local adaptation of two common plant species. Ecol. 88(2):424-433. DOI: 10.1890/00129658(2007)88[424:cvsfil]2.0.co;2

Meloni M, Perini D, Filigheddu R, Binelli G (2006) Genetic variation in five Mediterranean populations of Juniperus phoenicea as revealed by inter simple sequence repeat (ISSR) markers. Ann Bot 97(2):299-304. DOI: $10.1093 / \mathrm{aob} / \mathrm{mcj} 024$

Pate HR (1917) Madras District Gazeteers: Tinnevelly: Presidency of Madras

Pullaiah T, Chennaiah E (1997) Flora of Andhra Pradesh, Vol. 1. Scientific Publishers, Jodhpur

Ramachandran A (2017) Seed source variation for fruit, seed, seedling and camptothecin, an anti-cancer drug, in Pyrenacantha volubilis. MSc Thesis, University of Agricultural Sciences - Dharwad, Karnataka, India

Ramachandran A (2020) Genetic diversity and domestication of Pyrenacantha volubilis Wight, an anti-cancer drug yielding plant. PhD Thesis, Kerala Agricultural University, Kerala, India

Ramachandran A, Vasudeva R (2020) Clinal variation for fruit, seed and leaf morphological characteristics in natural populations of Pyrenacantha volubilis Wight: a rich source of anti-cancer drug. J Farm Sci 33(1):125-130

Ramachandran A, Vasudeva R, Ravikanth G, Shaanker RU (2021) Variation in seedling vigour and camptothecin content of Pyrenacantha volubilis Wight: insights for domestication. Genet Resour Crop Evol 68:10611071. https://doi.org/10.1007/s10722-020-01048-6

Ramesha BT, Suma HK, Senthilkumar U, Priti V, Ravikanth G et al. (2013) New plant sources of the anti-cancer alkaloid, camptothecine from the Icacinaceae taxa, India. Phytomedicine 20:522. https://doi.org/10.1016/j.phymed.2012.12.003

Rogers SO, Bendich AJ (1994) Extraction of total cellular DNA from plants, algae and fungi. In: Gelvin SB, Schilperoort RA (eds) Plant Molecular Biology Manual. Springer, Dordrecht, pp.183-190. https://doi.org/10.1007/978-94-011-0511-8_12

Rohlf FJ (1993) NTSYS-pc Numerical Taxonomy and Multivariate Analysis System version 1.8 Manual. New York: Applied Biostatistics, Inc. 
278 Sasidharan N, Renu G (2013) Pyrenacantha volubilis Wight. India Biodiversity Portal.

279 https://indiabiodiversity.org/biodiv/species/show/248952. Accessed 4 November 2020

280 Savolainen O, Pyhäjärvi T, Knürr T (2007) Gene flow and local adaptation in trees. Annu Rev Ecol Evol Syst 38:595-619. https://doi.org/10.1146/annurev.ecolsys.38.091206.095646

282 Vandrey JP, Stutz E (1973) Evidence for a novel DNA component in chloroplasts of Euglena gracilis. FEBS Lett 37(2):174-177. DOI: 10.1016/0014-5793(73)80452-1

284 Wandersee JH, Schussler EE (1999) Preventing plant blindness. Am Biol Teacher 61(2):82-86. https://doi.org/10.2307/4450624 
Figures

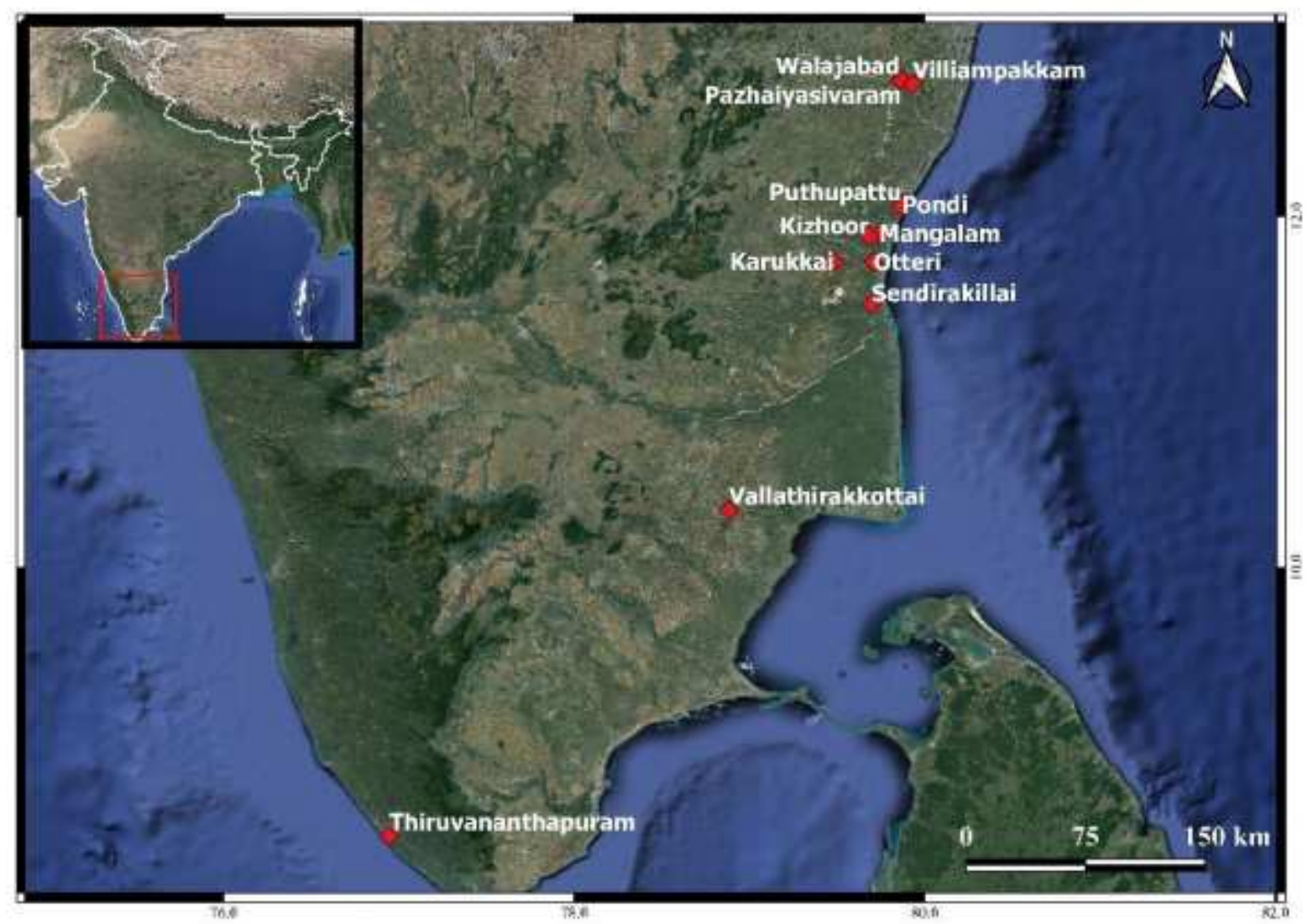

Figure 1

Map of study area

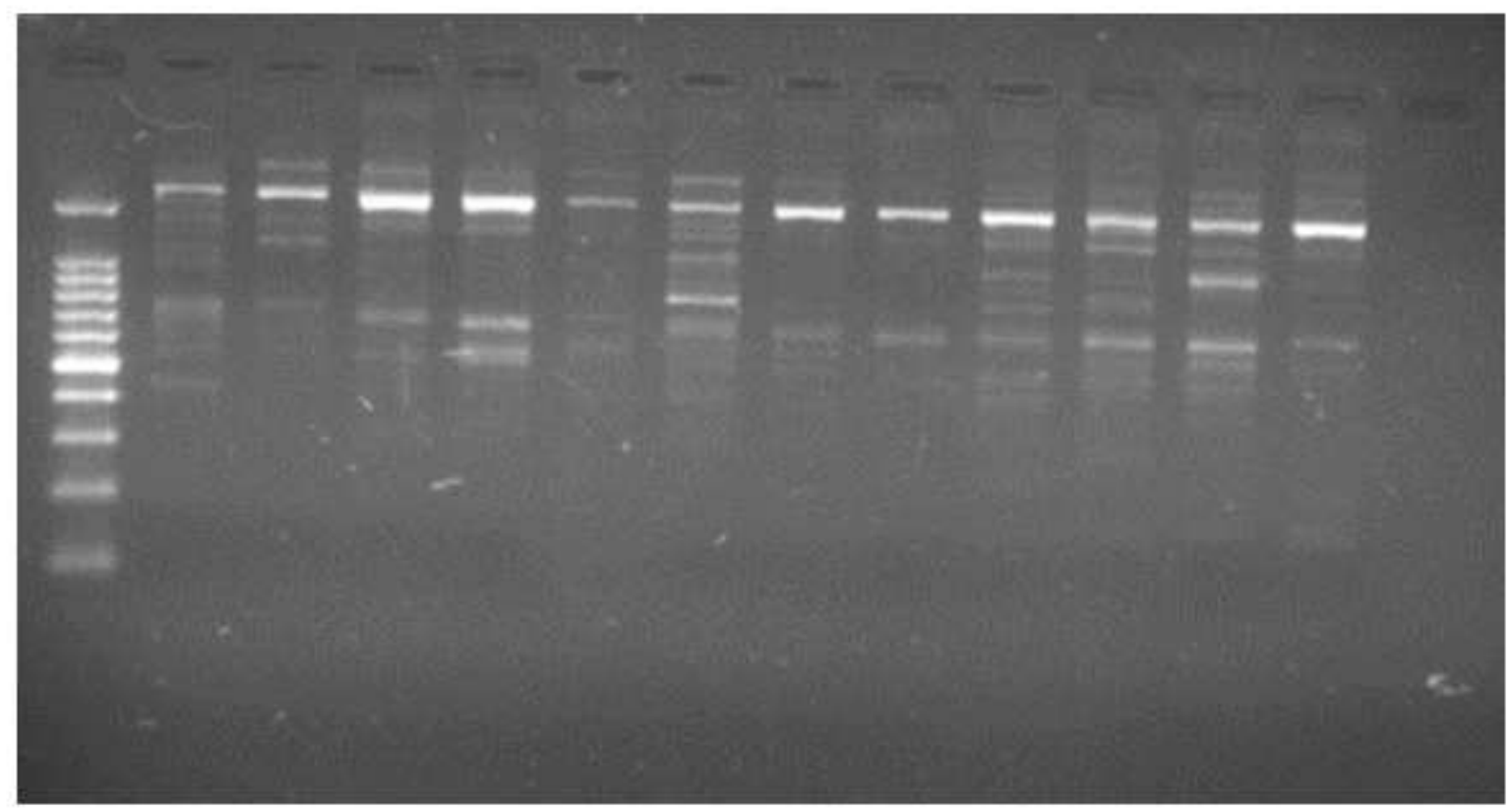

Figure 2 


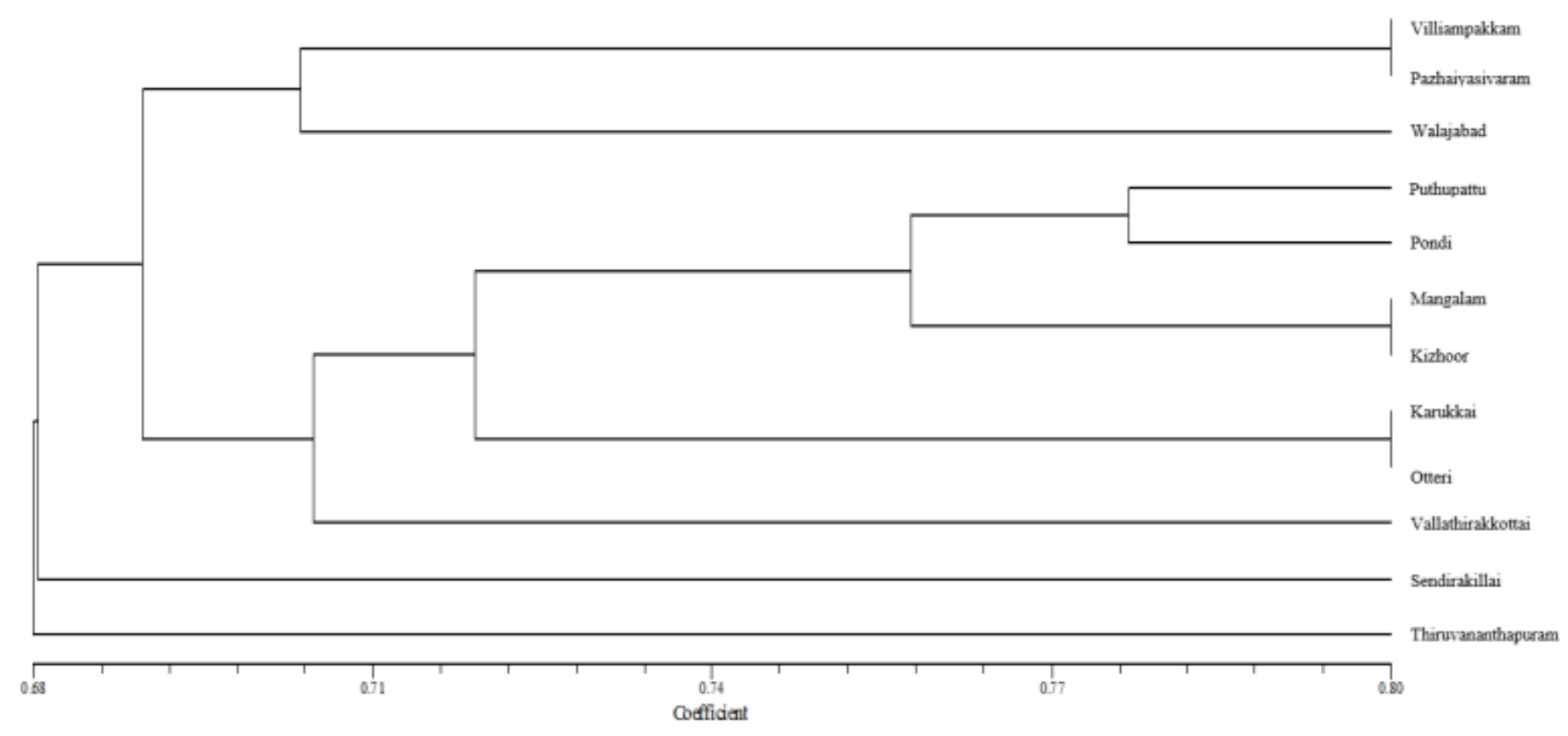

\section{Figure 3}

Hierarchical UPGMA dendrogram based on molecular (ISSR amplicon) data of 12 populations of P. volubilis from Kerala and Tamil Nadu

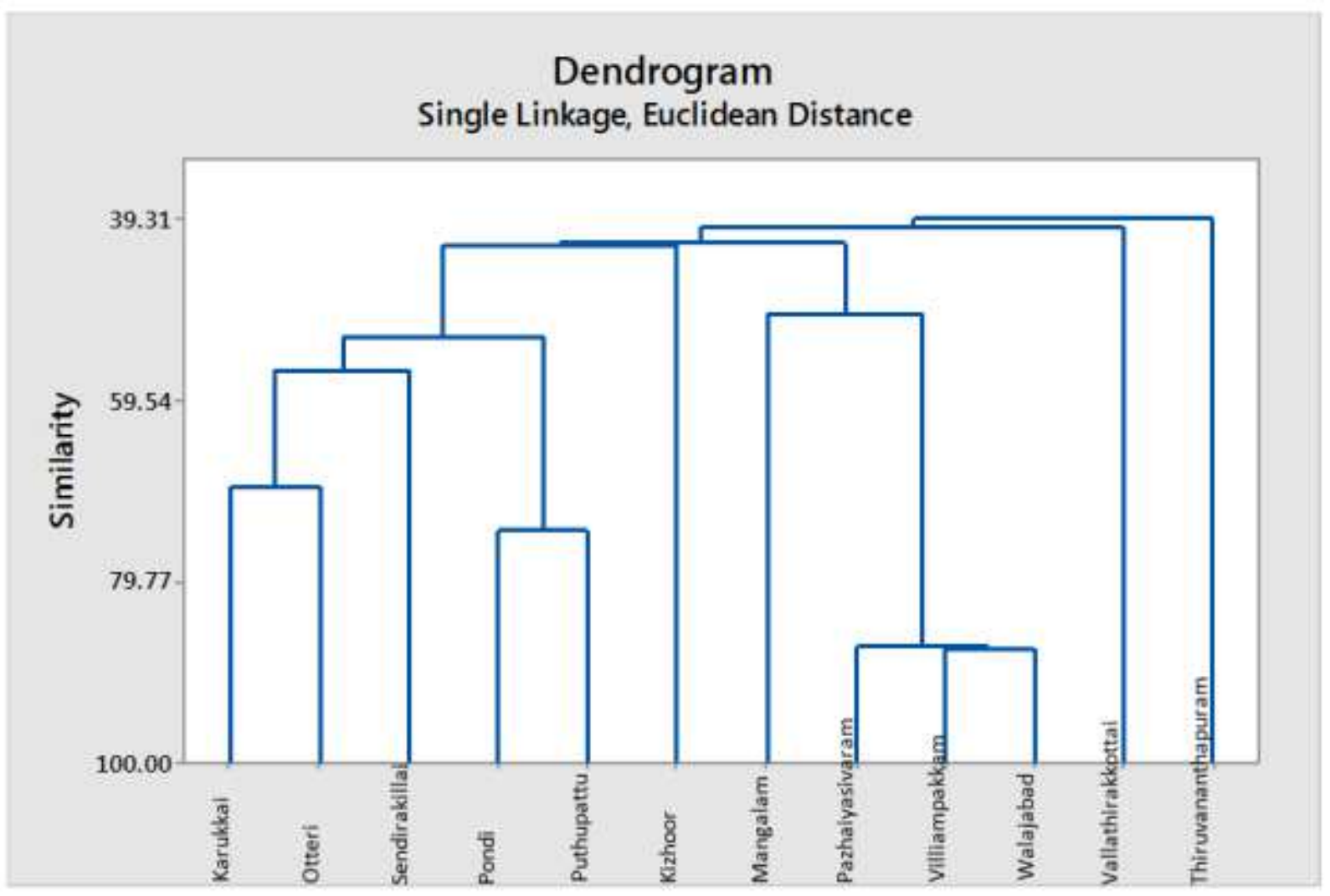

Figure 4 
Hierarchical Neighbour Joining $(\mathrm{NJ})$ tree clustering based on agro-morphological data of 12 populations of P. volubilis from Kerala and Tamil Nadu

\section{Supplementary Files}

This is a list of supplementary files associated with this preprint. Click to download.

- ArjunRamachandranSupplementarymaterial.pdf

- ArjunRamachandranGenResCropEvolFullTable.pdf 